\title{
Hegemonía comunicativa, participación y voces subalternas: notas desde las aulas con niños y niñas wichi
}

\section{Communicative hegemony, participation, and subordinate voices: notes from the classroom with Wichi children}

DOI: https://doi.org/10.32870/dse.v0i20.599

\section{Virginia Unamuno*}

\begin{abstract}
Resumen
Este artículo se enmarca en una investigación etnográfica y multisituada que busca dar cuenta de las prácticas educativas categorizadas por sus actores como bilingües e interculturales, en la región de El Sauzalito (Chaco, Argentina) en donde se escolarizan niñas y niños wichi. En este caso, el estudio se centra en la perspectiva de los niños sobre los contextos y las prácticas de los que forman parte. Para ello, tomo como eje de análisis el estudio de la participación situada y de las acciones interactivas corporizadas (Goodwin, 2000; Goodwin y Goodwin, 2004). Según se argumentará aquí, el análisis de los movimientos, las miradas y los gestos de los participantes permitirían reconstruir algunos sentidos sobre las actividades que ellos encarnan. Esto, en definitiva, ofrecería datos para entender los procesos de hegemonía comunicativa y la resistencia a través de voces subalternas que operan en los casos que se analizan.
\end{abstract}

Palabras clave: hegemonía comunicativa - silencios - wichi - Chaco - Argentina.

\begin{abstract}
This article is part of ethnographic and multisite research work that seeks to give an account of the educational practices categorized by their actors as bilingual and intercultural in the El Sauzalito region (Chaco, Argentina), where Wichi girls and boys are educated. In this case, the study focuses on the children's perspective on the contexts and practices of which they are part. To do this, I have taken as my axis of analysis the study of situated participation and interactive embodied actions (Goodwin, 2000, Goodwin \& Goodwin, 2004). As I will argue here, the analysis of the movements, looks and gestures of the participants could allow us to reconstruct some of the meanings of the activities they embody, providing us with data that would help us understand the processes of communicative hegemony and the resistance to it through the subordinate voices operating in the cases analyzed.
\end{abstract}

Key Words: communicative hegemony - participation - Wichi - Chaco - Argentina.

\footnotetext{
* Doctora en Filología (Lingüística). Centro de Estudios del Lenguaje en Sociedad (CELES). Universidad Nacional de San Martín-CONICET. Argentina.vir.unamuno@gmail.com
} 


\section{Introducción}

Este trabajo tiene origen en un reto: acercarse a través de la etnografía a la perspectiva de los niños y niñas wichi sobre los eventos de habla en que participan, en el marco de las instituciones donde se escolarizan. No ha sido tarea fácil, principalmente porque mi labor investigadora se centra en procesos que, si bien involucran a este grupo, toma como perspectiva la de los/ las docentes. Sin embargo, he intentado descentrar el ojo observador atendiendo a las huellas que dejan niños y niñas sobre los modos en que entienden lo que está pasando y considerar algunas pistas que me permiten aproximarme a su mirada sobre lo que se dice y sobre lo que se calla en estos contextos. Estas huellas y pistas son diversas y están diseminadas en diferentes materialidades: en gestos, miradas, movimientos, palabras y silencios. Tratar de darles un sentido me ha llevado a construir un relato ecléctico que espero pueda ser comprendido como un rompecabezas: un recorrido entre piezas diferentes que se orienta hacia una figura común.

El artículo está organizado del siguiente modo: en primer lugar, presentaré el contexto en donde trabajamos. Luego, haré una escueta presentación de la perspectiva que toma este trabajo, basada en el estudio de la participación. A continuación, analizaré algunas clases para ilustrar aspectos diversos de la perspectiva de niños/as sobre las situaciones escolares en las cuales participan. Finalmente, esbozaré algunas conclusiones.

\section{El contexto en donde trabajamos}

Las comunidades wichi se extienden a lo largo de un extenso territorio que va desde el sur de Bolivia hasta la provincia de Chaco, Argentina. Están, mayoritariamente, sitas a lo largo de dos ríos: el Bermejo y el Pilcomayo. Los wichi son pobladores ancestrales de estas tierras. A diferencia de otros pueblos nativos de Argentina, conservan en su mayoría la lengua propia, la cual es trasmitida fuertemente de generación a generación.

Diversas razones se han esgrimido para explicar la alta vitalidad de esta lengua: la mayoría de la población wichi habita en zonas rurales y, en parte, aislada de los centros urbanos donde el castellano es lengua mayoritaria. Asimismo, se ha considerado también que la trasmisión de la lengua entre los wichi está vinculada a las ideologías lingüísticas y a la cosmovisión propias: el fuerte peso de la lengua en los procesos de identificación y de construcción de pertenencias étnicas; el lugar de la lengua propia en la cosmogonía nativa (Unamuno y Romero-Massobrio, 2018).

Desde hace algunas décadas, la lengua wichi también está presente en las escuelas (Zidarich, 2001). Experiencias diversas y de diferente origen de lo que se podría denominar educación bilingüe e intercultural vienen teniendo lugar en los territorios wichi. Por lo general, tienen como meta la alfabetización en la lengua propia y su uso como recurso de mediación lingüística e intercultural para la construcción de saberes escolares en español. También, han tenido lugar experiencias educativas que buscan incorporar y hacer dialogar el currículum escolar con las prácticas culturales y los saberes wichi a lo largo de la escolaridad.

Diálo@os sobre Educación año 11 | número 20 | enero-junio 2020 | ISSN 2007-2171 
En la provincia de Chaco, lugar en donde trabajamos, las experiencias educativas bilingües e interculturales se han incrementado en la última década. Esto se ha relacionado, por un lado, con el cambio en las políticas lingüístico-educativas en dicha provincia, y por otro, con la creación de un centro de formación de docentes indígenas wichi sito en la localidad de El Sauzalito. Se trata de la sede del Centro de Investigación y Formación para la Modalidad Aborigen (CIFMA), institución pionera en Argentina en el campo de la educación intercultural bilingüe y la formación docente (Valenzuela, 2009; Valetto et al., 2018).

En el CIFMA, en los años noventa se formaron los primeros auxiliares docentes bilingües (ADA), primeros educadores wichi que entraron en las escuelas chaqueñas. Luego, a partir del siglo XXI, personas wichi del Chaco estudiaron la carrera de Maestro Intercultural Bilingüe y, luego, de Profesores Interculturales Bilingües (Unamuno, 2013). Estos tres perfiles de educadores/as wichi se encuentran actualmente en las escuelas de la zona (Ballena, Romero y Unamuno, 2015).

Más allá de la titulación que tienen, los/las docentes wichi trabajan en su mayoría como auxiliares. Esto quiere decir que asisten lingüísticamente y median interculturalmente durante las clases que imparte un docente no indígena que llamaremos, siguiendo la denominación de la zona, "maestro blanco". La mayoría de estos maestros blancos no hablan ni entienden la lengua wichi; sin embargo, están a cargo de las clases y de los procesos escolares que involucran a los niños y a las niñas wichi.

Los y las educadoras wichi obtienen en las escuelas diferentes perfiles. Como se dijo, la mayoría trabaja como auxiliares docentes. Sin embargo, el rol que ejercen en las aulas depende del tipo de escuela de que se trate. Según un estudio de nuestro equipo (Ballena, Romero y Unamuno, 2015), además del rol de auxiliares, los docentes wichi pueden: a) estar a cargo de una clase; b) estar a cargo de un espacio curricular particular denominado habitualmente "lengua y cultura wichi"; c) estar a cargo de parte de las asignaturas curriculares en formatos que llamamos "aulas compartidas".

En la mayoría de los casos, los y las docentes indígenas están sitos en educación inicial (Jardín de Infantes) y en los primeros cursos del nivel primario. Esto se explica en gran medida, por el modelo de educación bilingüe que impera en la zona y en Argentina en general. Nos referimos al modelo de educación bilingüe de transición que categoriza a la lengua indígena como puente para la adquisición de saberes lingüísticos y escolares en general en la lengua dominante. En la lógica de este modelo, el uso de la lengua propia obtiene sentido porque participa en la construcción de aprendizajes escolares, en español.

En este mismo orden de sentido, el lugar de los y las educadoras wichi muchas veces se limita a la traducción de las clases impartidas en castellano por docentes "comunes" (no bilingües) o a la mediación lingüística entre los contenidos escolares —en castellano- - y los niños y niñas. Aún hoy son pocas las experiencias que apuestan por un modelo alternativo de educación intercultural bilingüe o por modelos dirigidos a la revitalización o ampliación de dominios 
de uso de la lengua propia. Sin embargo, este tipo de modelos son los que actualmente discuten las/los educadores wichi, quienes están buscando introducir en las escuelas perspectivas propias sobre el currículum y sobre los modos de enseñar-aprender.

\section{La participación de los niños y niñas como recurso de construcción de sentidos}

En este contexto, puede ser interesante preguntarse por los modos en que los niños y niñas wichi dan sentido a las experiencias escolares en que participan. Para ello, me gustaría compartir tanto notas de campo como transcripciones de clase, y analizarlas tomando como eje el estudio de la participación corporizada en el marco de la etnografía como método.

Entiendo la participación como un proceso situado que se despliega temporalmente, integrado en su entorno físico, negociado activamente y reconfigurado por los y las participantes a través de acciones corporizadas (Goodwin, 2000; Goodwin y Goodwin, 2004). En este sentido, son relevantes las observaciones sobre los movimientos, las miradas y los gestos de quienes participan, las cuales dan pistas para reconstruir los sentidos sobre las actividades que encarnan. Así también, son relevantes las categorizaciones sobre los modos en que las interacciones se organizan y se materializan: me refiero específicamente a los usos de las lenguas, pero también a otros aspectos de la interacción como, por ejemplo, el volumen del habla.

Mi preocupación por estudiar la participación en este tipo de contextos se basa en algo que emerge en el campo y que el trabajo etnográfico me ha permitido contextualizar. Me refiero a las veces en que las y los docentes no indígenas describen a los niños y niñas wichi como "calladitos y tímidos". Y son notables, también, las veces en que se señala que no participan en clase. Sin embargo, según pude construir a lo largo de estos años, tal descripción no se corresponde con las formas en que se presentan frente a mí en las aulas, ni con la manera en que yo suelo describirlos en mis notas de campo. Esto me ha llevado a pensar que la descripción que hacen los/las docentes no indígenas está vinculada a los modos en que se posicionan frente a los niños y niñas wichi, y a los modos en que producen el sentido de lo que hacen y dicen en las aulas. Por lo tanto, según analizo, la descripción de los niños y niñas wichi como "calladitos y tímidos" podría interpretarse como una producción simbólica que atañe a los indígenas, y que se basa en el acallamiento de voces. "Lo silencioso" es propuesto, así como una construcción social vinculada a la hegemonía comunicativa (Briggs, 2005) que se despliega en las aulas con niñas y niños indígenas. La etnografía, creo, puede aportar con su método a la descripción de la misma y a la interpretación de los modos en que funciona.

El interés por estudiar la participación también radica en mi preocupación por las posibilidades y los límites que tienen niñas y niños de interactuar en los marcos escolares y, a partir de allí, reacomodar sus saberes y sus repertorios de habla. Esto se enmarca en una preocupación más amplia, relativa al rol del lenguaje en el acceso a derechos fundamentales por parte de la población indígena en mi país.

Diólo@os 
Para poder analizar esto, como he dicho, tomaré en cuenta los datos producidos en el marco de un trabajo etnográfico extenso y multisituado; es decir, un trabajo que busca la compresión de una situación compleja a través del relevamiento y la comparación analítica de diversos casos. Particularmente, tomaré en cuenta un conjunto o corpus de clases registradas en formato audiovisual y transcritas en parte. Así también, mis notas de campo que vengo produciendo desde el año 2010. Todos estos registros, enmarcados en la etnografía, me han permitido ir construyendo interpretaciones a partir no solo lo que se dice, sino especialmente de lo que se hace (y se hace al decir y al callar). Cito aquí a Julieta Quiros (2014: 51):

La experiencia etnográfica nos muestra que ese "decirnos" en modo alguno es literal: la gente nos dice (cómo es y cómo funciona el mundo) a través de lo que dice, pero también y de manera fundamental a través de lo que hace, de cómo lo hace, de lo que no hace, de lo que no dice, y — como nos enseñaron hace tiempo los pragmáticos del lenguaje- de lo que hace, intencionalmente o no, por intermedio de lo que dice.

\section{Andando las aulas}

Una cuestión importante en la construcción de la etnografía sociolingüística que vengo haciendo radica en sostener un trabajo prolongado en el terreno. Específicamente, en mi caso, en las aulas con niños y niñas wichi. Desde hace casi una década, comparto clases y experiencias educativas en donde ellos y ellas se escolarizan, y participo en calidad de formadora e investigadora en diferentes proyectos encabezados por educadores/as indígenas. Así, entre los años 2012 y 2015, trabajé en experiencias diversas llevadas a cabo en el Jardín de Infantes sito en la localidad de El Sauzalito. Paralelamente, participé en diversos proyectos en otras localidades aledañas: Tres Pozos (2012 y 2013) y Los Lotes (2015 y 2016).

Asimismo, en el marco de un proyecto del CIFMA que buscó relevar la situación de sus egresados, visité más de 13 escuelas sitas en el territorio wichi de la provincia de Chaco, en donde pude observar y filmar clases, así como entrevistar a docentes y a directivos/as.

Todo este bagaje de experiencias compartidas me ha permitido reconstruir cierto sentido común que recorre las aulas y que se materializa en las prácticas que observo y analizo. Desde este conocimiento del terreno y desde la identificación de las distintas posiciones y teorías sobre el mundo que coexisten (y dialogan o disputan el sentido común), he intentado construir interpretaciones que están arraigadas en el estudio particular de las formas en que se materializan los discursos y los sujetos. Para ello, me han sido útiles las herramientas analíticas del análisis del discurso y de la interacción (Fairclough, 1995; Gumperz, 1982).

Para este trabajo en particular, tomo en cuenta una selección de fragmentos o momentos de clase cuyo análisis busca pincelar una cierta atmósfera que recorre la zona donde trabajo, y que me permite señalar ciertos aspectos que considero interesantes para dar cuenta de la perspectiva de los y las niñas sobre los procesos escolares de los que son parte. 


\section{La clase de Clementina}

La primera clase que quiero compartir sucede en el Jardín de Infantes de la localidad de El Sauzalito. Como es común en la zona, los niños y niñas son separados por razones de lengua entre clases distintas (Unamuno y Nussbaum, 2017). En esta clase, como en la mayoría, hay dos docentes: una maestra wichi y una no wichi. Ambas están en la misma clase, aunque suelen tener roles claramente diferenciados.

Estas aulas del Jardín de Infantes enmarcan las primeras instancias de socialización escolar de los niños y niñas wichi. Y ellas, muchas veces, albergan las primeras situaciones en las cuales se utiliza el castellano y en las cuales participan las niñas y niños wichi.

Desde pequeños, aprenden formatos de participación que son bilingües. En muchas de las aulas, esto implica saber distinguir entre momentos de la clase que se suceden en una lengua que están aprendiendo y que, como tales, se presentan opacos, y otros, que se producen en la lengua que conocen. Sin embargo, estas interacciones en la lengua familiar muchas veces suceden en la lateralidad de las secuencias principales de la interacción. Pero se trata, no obstante, de secuencias cruciales (Unamuno y Nussbaum, 2017).

Estas secuencias laterales parecen pasar desapercibidas desde la perspectiva centrada en la persona adulta. Sin embargo, son fundamentales desde la perspectiva de las y los niños: son ellos quienes muchas veces las inician y las protagonizan.

La clase que quiero compartir sucede con niños y niñas de 4 y 5 años. Es parte de un proyecto que hacemos colaborativamente sobre el trabajo de las mujeres wichi con el barro para la elaboración de tinajas. Este proyecto, que culminó hace poco con la elaboración de un libro de cuentos y relatos de experiencias, incluyó diversos momentos como los que quedaron retratados en esta transcripción. 
Fragmento 1: Iñot (barro)

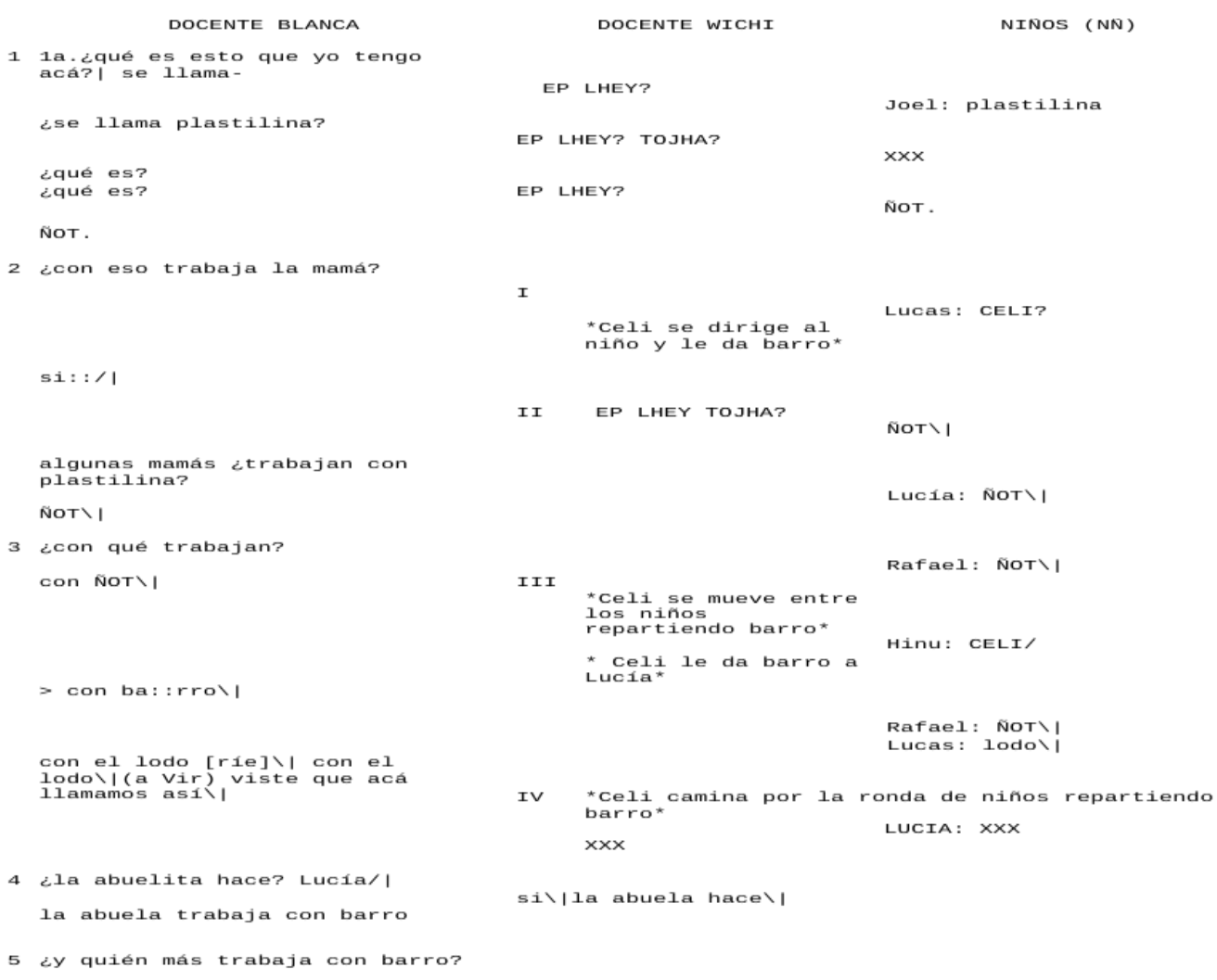

En este proyecto, las docentes planificaron una primera clase en la cual los niños debían comparar el trabajo que realizan con plastilina en el Jardín de Infantes con el trabajo de barro que realizan las mujeres. Para ello, la docente no wichi saca de una caja un trozo de barro y presenta el material. Pregunta a los y las niñas el nombre del material. La intervención de la educadora wichi media constantemente en la conversación. No solo traduce, sino que anticipa posibles malentendidos. Uno de los niños propone "plastilina". La docente no indígena vuelve a hacer la pregunta buscando una alternativa. Los niños y niñas buscan la respuesta entre su repertorio de habla. Parecen desconocer la palabra "barro" y proponen (i)ñot, barro en wichi. La docente insiste una y otra vez buscando la palabra en español. Finalmente, acepta la respuesta en wichi.

En la secuencia 2, la docente pregunta por el trabajo de sus madres. Las niñas y niños tardan en responder, y ella insiste. Luego, reformula su pregunta y continúan diciendo ñot, sin entender lo que se les pregunta. Finalmente, en la secuencia 3, luego de reformular la pregunta nuevamente, recoge la respuesta en wichi (ñot) y la reformula en español ("con barro"), mo- 
dalizando el enunciado con un alargamiento vocálico. Otro de los niños vuelve a decir ñot, e inmediatamente otro niño dice "Iodo". En ese momento, la docente acepta la respuesta, pero, dirigiéndose a la investigadora, explica que se trata de una variante local de la palabra "barro".

Mientras todo esto sucede, Lucas, Hin'u y Lucía reclaman la atención de Celis, la educadora wichi, que se mueve constantemente entre las sillitas en donde están sentados. No sólo le piden un trozo de barro, sino que van interactuando con ella, de uno en uno, para contrastar sus ideas sobre lo que está pasando, y sobre lo que se espera que digan (y hagan).

En un momento, Lucía dice algo en wichi a la educadora que yo no llego a comprender. Celis se dirige físicamente a ella. Desde esta posición cercana, media entre la niña y la docente blanca, aportando a la conversación lo que la niña le ha dicho en wichi desde la lateralidad de la conversación. Lucía ha conseguido la atención de Celis y, apoyándose en ella, ha podido contribuir a la interacción de la clase.

\section{La clase de Mario}

En el segundo caso, consideraré las notas de mi visita a segundo grado $B$, en la cual trabajan juntos un docente no wichi (Raúl) y un auxiliar docente bilingüe (Mario).

Durante una semana observé sus clases para contrastar el uso de las lenguas wichi y español en este tipo de contextos que denomino bigestionado. Si bien el foco de observación se situó en el uso de las lenguas en las clases, consideraré aquí mis notas respecto al modo en que en ellas se desenvuelven con las niñas y niños. El análisis de su actuación se propone como una entrada al sentido de lo que pasa y se hace en estas aulas.

\section{Viñeta 1}

Las clases están organizadas en materias (matemática, lengua castellana y ciencias). Hoy toca matemática. Raúl está sentado en el escritorio del docente, situado en el lateral izquierdo, junto a la pizarra. Sobre el escritorio está el libro de asistencia y un manual de segundo grado. También su cartuchera y el borrador. Mario me saluda y yo me ubico en el fondo de la clase, en un banco vacío. Mario entra en la clase con los niños que vienen del recreo. Me saluda en wichi y yo le respondo. Me sonríe. Nos conocemos desde hace años, porque él es el marido de una colega wichi con quien trabajé en otra escuela. Mario se queda de pie en el fondo de la clase, con la espalda recostada en la pared. Los niños van ubicándose en sus bancos y sacan sus cuadernos del estante de los bancos o de sus mochilas. Cuando todos parecen estar sentados, Raúl se para de su escritorio y les dice que copien unas cuentas que pondrá en el pizarrón. Los niños sacan sus lápices y copian. Mario sigue de pie hasta que una de las niñas se da vuelta y lo mira. Él se acerca hacia ella sin palabra. Y en wichi le dice que copie las cuentas del pizarrón. Se inclina hacia ella y va orientándola en la copia. "Es nueva" me dice cuando se acerca a mi lado. Raúl vuelve a su escritorio. Hay un gran silencio aparente. Mario, mientras Raúl rellena el libro de asistencia, va pasando por los bancos en la medida que los niños lo miran. Luego, Raúl da por terminado el tiempo de resolución de la tarea, y pide a los niños los resultados de las cuentas. Nadie responde verbalmente.

\section{Diólo@os}


Sin embargo, Mario se dirige a una de las niñas que ya ha terminado, y tocándole el hombro le indica que pase al frente. Ella resuelve la primera cuenta en el pizarrón. Los otros niños hablan en voz baja entre ellos y con Mario. Lo hacen en wichi.

Quiero llamar la atención aquí sobre los formatos de participación que proponen o en los que participan los niños y niñas wichi de segundo grado. A través del movimiento, de la mirada o de un gesto que parece sutil, contrastan sus ideas sobre lo que está sucediendo con la persona adulta de la clase que habla su lengua. Las y los niños seleccionan a Mario como destinatario y es a él a quien se dirigen las miradas durante la clase que dicta el otro docente.

Por su parte, Mario se mueve en la clase en un sentido distinto que su colega no wichi. Niños y docente, a través del movimiento y de las trayectorias de las miradas y gestos, consiguen reconfigurar las escenas que observo. El maestro no indígena, situado en el centro de la escena que construye el mobiliario, se va desdibujando desde la perspectiva de lo que sucede entre los bancos del aula.

Como ha señalado Goffman (2001), participar requiere una coordinación sutil pero compleja entre los participantes, quienes negocian activamente los marcos de participación que cambian constantemente. Participar en una interacción social requiere la correlación de diferentes modalidades semióticas. La mirada y la posición del cuerpo, el gesto y la postura participan en la creación del significado interaccional (Mondada, 2011).

En el caso que analizo, estos elementos multimodales se coordinan de una manera particular para establecer formatos de participación paralelos a lo que sucede en la escena principal, y dan pistas para acercarse a los modos en que las niñas y niños dan sentido a lo que está pasando. La producción semiótica de otros modos de participación se hace evidente principalmente frente a situaciones problemáticas, como cuando tienen alguna pregunta respecto a la tarea 0 cuando quieren compartir los avances de sus trabajos individuales. Niñas y niños ponen en juego múltiples recursos que consiguen definir la situación y dar cierto sentido a la actividad en que participan.

\section{En clase de Alejandra}

Viñeta 2

La clase empieza en español y Alejandra les propone contarles un cuento. Lo hace poco a poco, usando unas láminas de colores muy bonitas. Los niños la miran extrañados. Mi cámara intenta captar ese momento y hace un zoom sobre el grupo de niños, hasta que se detiene en una niña que está a punto de llorar. La niña mira a Alejandra y le dice "vos no". Está a punto de llorar. Alejandra me mira, como si buscara la aprobación para cambiar de lengua. La niña le pide que narre el cuento en wichi. Alejandra le explica en wichi que es solo un rato, que ella puede hablar wichi si quiere. La nena sigue incómoda y finalmente Alejandra opta por narrar el cuento en su lengua. 
Hay algo que recuerdo de esta clase y que no es fácil para mí explicar. Ese "vos no", reclama algo que va más allá de cierta correspondencia entre lengua e interlocutor. Va más allá del reclamo hacia la docente wichi respecto a la lengua que ella está empleando durante la clase. Remite a las veces en que los docentes narran cuentos en español como si las y los niños entendieran, como si sus silencios, sus miradas perdidas, fueran señales de algo que "está pasando". Como si no fuera evidente que gran parte de los niños wichi — como los que observo en la clase de Alejandra - no pueden entender lo que les encantaría entender.

En esta clase de español como lengua segunda, Alejandra, docente wichi, se había propuesto contar el cuento en español. Sin embargo, cambia de lengua y retoma el relato en wichi. La niña le sonríe. Luego de la clase, algunos niños/as se acercan a su docente y le piden una copia del cuento. En un rincón, tres de las niñas se narran mutuamente el cuento.

\section{La clase de Luis}

Los libros de cuentos maravillan a los niños y niñas de la escuela primaria de la localidad de Los Lotes, donde trabajamos Luis y yo. Las ilustraciones, las formas del libro, las formas de las letras. Una mañana asistí a una clase en que el maestro Luis contaba un cuento sobre una vaca que quería ser blanca. Primero leyó el cuento mientras las niñas y niños disfrutaban de las imágenes del libro. ${ }^{1}$ Luego, Luis contó el cuento en wichi y reían sin parar. Estaban fascinados con la historia. Y todos querían llevarse el libro a casa para contarlo a sus familias.

El libro cuenta la historia de una vaca que no quiere tener sus manchas y quiere ser como cualquier otro animal "sin manchas". Luego de la narración, Luis les preguntó qué le pasaba a la vaca. Matías dijo en voz alta y en wichi: "no quiere ser ella misma. Quiere ser otro animal". Luis prosiguió: “¿y a ustedes les pasa como a la vaca?"El mismo Matías dijo: "A mí a veces me gustaría ser criollo".

\section{La clase de Luciano}

\section{Viñeta 3}

Cuando llegué a la clase de la escuelita de Tres Pozos había dos maestros en el aula: Luciano, docente wichi, y Pedro, docente no indígena. Luciano estaba sentado, como es habitual en estas clases, junto a los niños en el fondo de la clase. Pedro, por su parte, al frente, junto al pizarrón. Puse mi cámara en el frente de la clase, tal y como habíamos pactado.

Pedro inicia la clase presentándome a los niños y niñas, y explicándoles que soy la profesora de Luciano. Luego, con un gesto sutil pero autoritario, le señala a Luciano que reparta unas fotocopias que saca de una carpeta. Mientras Luciano se acerca al escritorio de Pedro, una niña pequeña me pregunta mi nombre. Luego, me dice en wichi que tiene miedo. “A qué?”, le pregunto. Lo mira a Pedro. “A mí también me da miedo”, le digo. "Grita", me dice".

1 “Cuero negro, vaca blanca” ilustrado por Pablo Bernasconi.

\section{Diólo@os}


Estas notas hacen referencia a otro aspecto de la participación de los niños y niñas wichi que pocas veces es tenido en cuenta, pero que sin embargo es notable. Me refiero a la manera en que ellos interpretan el volumen de la voz de los docentes blancos y los significados que le otorgan.

A grandes rasgos, la percepción que tenemos quienes no somos wichi es que ellos hablan "bajito". Recuerdo una clase de lengua wichi en que fui estudiante. La clase estaba llena y yo me senté en el fondo para tomar nota. Me sentí sorda ese día. Porque casi no alcanzaba a percibir lo que el profesor explicaba, pero notaba, no obstante, que todos los demás tomaban apuntes y hacían preguntas y comentarios sobre lo que se discutía. Al finalizar la clase, le pregunté a mis compañeros si no habían notado que el profesor hablaba muy bajito. Ellos se rieron, y me dijeron que no, que tenía la sordera del blanco.

El volumen de la voz es otro de los rasgos semióticos que muchas veces es menospreciado en relación con la participación. En los casos que analizo, sin embargo, es fundamental. Porque se trata de un rasgo que es categorizado en relación con el sentido de las interacciones; específicamente, a los sentidos que niños y niñas dan a la interacción en las aulas con personas adultas blancas.

Para los adultos wichi, el hablar con niños y niñas implica un cuidado especial porque consideran que ellos "tienen un oído sensible". La voz baja, el susurro, y la selección de palabras "suaves" se considera parte de los modos de crianza que enmarcan contextos positivos para los niños.

En contraste, nosotras, las personas blancas, gritamos y, según ellos, parecemos siempre enojados. En general, no terminan de entender por qué. Sin embargo, el grito y el enojo es parte de su experiencia corporal y sensible en las aulas. Experiencias que distan ampliamente de aquellas amigables que inviten a participar.

\section{La clase de Macarena}

Macarena es una docente no wichi que enseña en un paraje cerca de El Sauzalito. Este fragmento de las observaciones de clase me sirve para pensar en otros aspectos de la mirada de los niños y niñas sobre lo que sucede en las aulas en donde se escolarizan.

Como señalé, la mayoría de los docentes no indígenas no hablan la lengua de los niños. Sin embargo, este desconocimiento es descrito en las interacciones como algo no problemático, como si no existiera. Las interacciones escolares en que los y las docentes no indígenas están solos (sin auxiliares bilingües), se producen de tal modo que no dejan rastro de estar situadas en contextos exolingües. Más bien, indexan una ficción que es localmente producida pero socialmente sostenida: que los niños y niñas wichi entienden y hablan castellano. Como contraparte, su silencio es descrito y actuado como una "opción cultural". 
Sin embargo, puede ser relevante señalar aquí la tensión entre silencio y hegemonía comunicativa. O más bien, entre el silencio como recurso y lo silencioso como producto. En las aulas con niños wichi esta diferencia es fundamental tanto desde el punto de vista teórico como metodológico. Desde el punto de vista teórico, invita a revisar la oposición entre lo verbal y lo no-verbal y, desde el punto de vista metodológico, implica considerar lo multimodal como dato.

La noción de hegemonía comunicativa que se emplea aquí se inserta en los trabajos de la etnografía del habla y viene a señalar algo que no se limita a la ideología lingüística, sino que va más allá: la hegemonía se vincula con la naturalización y la saturación ideológica. En el caso que se analiza aquí, se relaciona con lo que pareciera no escucharse, no verse, no registrarse: la voz de los niños y niñas - y la lengua en que se materializa — se hace invisible, inaudible (Unamuno, 2019).

Esto está vinculado con los modos en que las clases están estructuradas: el uso de múltiples recursos que se orientan a minimizar la participación de las niñas y niñas en ellas. Por ejemplo, la prominencia de preguntas cerradas que licitan respuestas mayormente no verbales; de enunciados incompletos que proyectan su estructura sintáctica en respuestas muy formateadas; de tareas monológicas, etcétera.

Aquí quiero traer un fragmento de la clase de Macarena, de Los Lotes.

\section{Viñeta 4}

Maca es criolla. Lleva casi 20 años trabajando como maestra "común" en la zona y conoce a los wichi desde su infancia. En la primera de mis visitas a su clase, Maca entra conmigo al aula. Parece enojada. Los niños están sentándose aún en los bancos, y miran a Maca con miedo. Maca, en voz alta y con tono autoritario, dice: "A ver... ¿nosotros somos personas o ututus (lagartijas)?" “Personas" responden los niños al unísono. "Entonces no muevan la cabeza como ututus. Miren hacia el frente. Bien sentados. Los hombros rectos. Somos personas. Per-so-nas". Maca se gira para anotar la fecha en la pizarra. Nicolás, un niño wichi que conozco desde pequeño, se ríe y con su mano derecha en la sien me hace el gesto de "chiflada" refiriéndose a su maestra.

Aquí me interesa particularmente el gesto de Nicolás. Porque de algún modo me hace releer las notas que tomé en estas clases. En estas notas, observaba especialmente la no-participación de los niños y niñas; el modo en que Macarena hacía como que sus clases eran "normales" mientras que los niños parecían ausentes o, físicamente, se ausentaban: marchaban de la clase por la puerta o la ventana y no volvían. Poco a poco, había menos niños y niñas en el aula, pero Maca seguía explicando cuentas o pidiendo que completaran múltiples fotocopias que, luego, debían pegar en el cuaderno.

Las ideas en torno al no ver, no mirar, no escuchar, no decir, aparecen como gestos vinculados a la no-participación. Formatos de participación que producen ausencias. Nicolás, no obstan-

Diálo@os año 11 | número 20 | enero-junio 2020 | ISSN 2007-2171 
te, me da otra señal. A través de su gesto me indica que hay algo anómalo en todo esto, y que ellos lo saben. Me permite pensar que en otra lectura de lo que sucede: ellos pueden aprender -y lo hacen- a interactuar en estas clases desde la no-participación; sin embargo, esto no quiere decir que lo que sucede les parezca "normal".

\section{A modo de cierre}

En este trabajo, he intentado aproximarme a la perspectiva de los niños y niñas a través del análisis de la participación. La hipótesis metodológica es que su estudio puede dar pistas de los modos en que ellos dan sentido a lo que está pasando en las aulas en donde se escolarizan.

A través de diferentes aulas y escenas, he intentado construir un relato ecléctico que a base de pinceladas pueda dar sentido a un rompecabezas. Como he señalado, mi interés por la participación se basa en que considero que esta es la base de los procesos de construcción de saberes. En este sentido, tomo cuatro aspectos de la participación desde el punto de vista de los niños y las niñas:

- La forma en que ponen en juego sus recursos semióticos para resolver las actividades que se les proponen.

- La forma en que resitúan y redefinen los marcos de participación que los involucran.

- La forma en que categorizan las situaciones de las que son parte, incluyendo a las formas de bilingüismo que en ellas se despliegan.

- La forma en que interpretan los recursos semióticos disponibles en las aulas, incluyendo el volumen del habla y el control de los cuerpos.

Estos aspectos son presentados aquí para discutir la descripción que se hace de los niños y niñas como "calladitos y tímidos", así como para dar sentido a los modos en que se evalúa, desde perspectivas no wichi, su participación en las aulas. Así también, su análisis pretende — sin la certeza de conseguirlo- dar voz a los y las niñas y sus miradas sobre procesos cruciales en que se los involucra: la escolarización.

Es común en Los Lotes que las madres estén presentes en las aulas del Jardín de Infantes. Están en un rincón. Sentadas mirando lo que pasa. De tanto en tanto, los y las niñas las miran y ellas los miran también, acompañándolos en este transcurrir. Para ellas, dejar a los niños y niñas en la escuela es un proceso laborioso que involucra confianza en las personas adultas de las instituciones escolares. Las y los educadores wichi son una pieza clave en este sentido. Lo es para los niños y niñas, lo es para las madres, lo es para mí. Ellos permiten que todo este transitar plagado de arbitrariedades se sienta un poco menos raro, menos loco. 


\section{Referencias}

Ballena, C., L. Romero y V. Unamuno (2015). Formación docente y educación plurilingüe en el Chaco: informe de investigación. Segunda parte. (Informe inédito), 2016.

Briggs, Charles L. (2005). Perspectivas críticas de salud y hegemonía comunicativa: aperturas progresistas, enlaces letales. Revista de Antropología Social, 14.

Fairclough, N. (1995). Critical Discourse Analysis. The Critical Study of Language. Londres: Longman.

Goodwin, Ch. (2000). Action and embodiment within situated human interaction". Journal of Pragmatics, 32, 1489-1562.

y M.H. Goodwin (2004). Participation. En A. Duranti (ed.). A companion to linguistic anthropology. Oxford: Blackwell, 222-244.

Gumperz, John J. (1982). Discourse Strategies. Oxford: Oxford University Press.

Mondada, L. (2011). Understanding as an embodied, situated and sequential achievement in interaction. Journal of Pragmatics, 43(2), 542-552.

Quiros, J. (2014): Etnografiar mundos vívidos. Desafíos de trabajo de campo, escritura y enseñanza en antropología. En proceso de publicación.

Unamuno, V. (2013). Gestión del multilingüismo y docencia indígena para una educación intercultural bilingüe en Argentina. Praxis Educativa, 7, 31-54.

y L. Nussbaum (2017): Participation and language learning in bilingual classrooms in Chaco (Argentina) / Participación y aprendizaje de lenguas en las aulas bilingües del Chaco (Argentina). Infancia y Aprendizaje/ Journal for the Study of Education and Development. DOI: 10.1080/02103702.2016.1263452

Unamuno, V. (2019). Sobre 'lo silencioso'y 'lo bilingüe' en las aulas con niños wichi en la Provincia de Chaco. En V.Zavala, S. de los Heros y M. Nino-Murcia (eds.). Hacia una sociolingüística crítica: desarrollos y debates, Lima, en prensa.

Valenzuela, E.M. (2009). Educación Superior Indígena en el Centro de Investigación y Formación para la Modalidad Aborigen (CIFMA): génesis, desarrollo y continuidad. En D. Mato (ed.). Instituciones Interculturales deEducación Superioren América Latina. Procesos de construcción, logros, innovacionesy desafíos. Caracas: Instituto Internacional de la UNESCO para la Educación Superior en América Latina y el Caribe, 79-102.

Valetto, R., V. Unamuno, F. Valetto y C. Fernández (2018). Representaciones respecto de las prácticas docentes en contextos de Educación Bilingüe Intercultural. En: Ministerio de Educación, Cultura, Ciencia y Tecnología, Investigación en los Institutos Docentes. Inclusión, trayectorias y diversidad cultural. Buenos Aires: Ministerio de Educación, Cultura, Ciencia y Tecnología. 